\title{
2D-SHEFFER-MITTAG-LEFFLER POLYNOMIALS: PROPERTIES AND EXAMPLES
}

\author{
Subuhi Khan, Mahvish Ali And ShakeEl Ahmad Naikoo
}

\begin{abstract}
In this work, the 2D-Sheffer polynomials and the Mittag-Leffler polynomials are combined to introduce the family of the 2D-Sheffer-Mittag-Leffler polynomials. The generating function, quasi-monomial properties and series definition of these polynomials are established. Examples of some members belonging to this family are considered. The graphs of some hybrid special polynomials are also drawn for suitable values of the indices.
\end{abstract}

Mathematics subject classification (2010): 33C45, 33C99, 33E20.

Keywords and phrases: 2D-Sheffer polynomials, Mittag-Leffler polynomials, generating function.

\section{REFERENCES}

[1] P. Appell, Sur une classe de polynômes, Ann. Sci. École. Norm. Sup., 9, 2 (1880), 119-144.

[2] H. Bateman, The polynomial of Mittag-Leffler, Proc. Nat. Acad. Sci. U.S.A., 26, 8 (1940), 491-496.

[3] C. Cesarano, Operational Methods and New Identities for Hermite Polynomials, Math. Model. Nat. Phenom., 12, 3 (2017), 44-50.

[4] Y. B. CHeIKH, Some results on quasi-monomiality, Appl. Math. Comput., 141, (2003), 63-76.

[5] G. DatToli, Hermite-Bessel and Laguerre-Bessel functions: A by-product of the monomiality principle, Advanced Special Functions and Applications (Melfi, 1999); 147-164, Proc. Melfi Sch. Adv. Top. Math. Phys. 1, Aracne, Rome, 2000.

[6] G. Dattoli, S. Lorenzutta, G. Maino, A. Torre and C. Cesarano, Generalized Hermite polynomials and super-Gaussian forms, J. Math. Anal. Appl., 203, 3 (1996), 597-609.

[7] S. Khan, N. RaZA AND M. ALI, Finding mixed families of special polynomials associated with Appell sequences, J. Math. Anal. Appl., 447, (2017), 398-418.

[8] S. KhAN AND M. RiYASAT, Determinantal approach to certain mixed special polynomials related to Gould-Hopper polynomials, Appl. Math. Comput., 251, (1996), 599-614.

[9] S. KHAN, M. W. M. AL-SAAD AND G. YASMIN, Some properties of Hermite-based Sheffer polynomials, Appl. Math. Comput. 217, 5 (2010), 2169-2183.

[10] Subuhi Khan, Ghazala Yasmin, Rehana Khan and N. A. M. Hassan, Hermite-based Appell polynomials: Properties and applications, J. Math. Anal. Appl. 351, (2009) 756-764.

[11] S. Khan, G. YASmin And N. AhmAD, On a new family related to truncated exponential and Sheffer polynomials, J. Math. Anal. Appl., 418, (2014), 921-937.

[12] S. Roman, The Umbral Calculus, New York: Academic Press, 1984.

[13] I. M. SHEFFER, Some properties of polynomial sets of type zero, Duke. Math. J., 5, (1939), 590-622.

[14] H. M. Srivastava, S. Araci, W. A. Khan AND M. AcikgöZ, A Note on the Truncated-Exponential Based Apostol-Type Polynomials, Symmetry, 11, 4 (2019), 538; https://doi.org/10.3390/sym11040538.

[15] H. M. Srivastava, M. Riyasat, S. Khan, S. Araci And M. Acikgöz, A new approach to Legendre-truncated-exponential-based Sheffer sequences via Riordan arrays, Appl. Math. Comput., (2019); https://doi.org/10.1016/j.amc.2019.124683.

[16] H. M. Srivastava, G. Yasmin, A. Muhyi and S. Araci, Certain results for the twice-iterated 2D q-Appell polynomials, Symmetry, 11, 10 (2019), 1307; https://doi.org/10.3390/sym11101307.

[17] J. F. STEFFENSEN, The poweroid, an extension of the mathematical notion of power, Acta. Math., 73, (1941), 333-366. 
[18] A. WrÜLICH, Beam-Life Time in Storage Rings, CERN Accelerator School, 1992.

[19] G. Yasmin, A. Muhy And S. ARACI, Certain results of q-Sheffer-Appell polynomials, Symmetry, 11, 2 (2019), 159; https://doi.org/10.3390/sym11020159. 